\title{
An Assessment of Leadership Styles and Employee Performance in Small and Medium Enterprises in Yola, Adamawa State, Nigeria
}

\author{
Fadimatu Jalal-Eddeen \\ College for Continuing Education, Department of Economics, Adamawa State Polytechnic, Yola, Adamawa State, Nigeria \\ Email address: \\ fadjals@gmail.com
}

\section{To cite this article:}

Fadimatu Jalal-Eddeen. An Assessment of Leadership Styles and Employee Performance in Small and Medium Enterprises in Yola, Adamawa State, Nigeria. International Journal of Economics, Finance and Management Sciences. Vol. 3, No. 3, 2015 , pp. 319-324. doi: $10.11648 /$ j.ijefm.20150303.29

\begin{abstract}
Background: SMEs are generally regarded as an important engine driving the growth of many economies as well as providing opportunities for job creation and rural development, which accounts for $10 \%$ of the total manufacturing output and $70 \%$ of employment in Nigeria. In view of the importance of SMEs, a sector that has the potential for solving Nigeria's unemployment and poverty problems, it is important to understand and critically examine the factor(s) impeding its growth to be able to proffer solutions that would identify the strengths and weaknesses, analyze and assess problems in the SMEs and provide information on the effects leadership has on employee job performance. Some of the advantages claimed for SMEs include encouragement of entrepreneurship, greater likelihood for SMEs to utilize labour intensive technologies positively impact on employment generation. As argued by some researchers, the actual influence of leaders on organizational outcomes is overrated and romanticized as a result of biased attributions about leaders. Study Design: This quantitative cross-sectional study in the form of survey, administered questionnaire to randomly selected participants. The sample size for the quantitative component was 100 comprising of 21 management staff and 79 employees from the five selected SME firms in Yola, Adamawa State. In-depth interview involving 12 personnel (4 management staff and 8 employees) was also used. Results: Results were presented using both descriptive and inferential statistics. It was evident that the predominant type of leadership in the enterprises studied is participative democracy, and that leadership styles have effect on the performance of employee. This was supported by the fact that results of the computed Chi square test (24.55 and 17.39) for the first and second hypotheses (at $\mathrm{P} \leq 0.05, \mathrm{df}=95)$ are greater than the tabulated $(0.078$ and 0.136$)($ at $\mathrm{P} \leq 0.05, \mathrm{df}=95)$. Conclusion: This research was able to show that leadership styles have effect on the employee performance and also the leadership style in use is participative democracy.
\end{abstract}

Keywords: Leadership, Small and Medium Scale Enterprises, Yola, Adamawa, Nigeria

\section{Introduction}

In developing countries, interest in the development of SMEs and their contribution in the development process continue to be in the forefront of policy debates ${ }^{2}$. There are numerous advantages claimed for SMEs and these include the encouragement of entrepreneurship, the greater likelihood that SMEs will utilize labour intensive technologies and thus have an immediate impact on employment generation. As a result of these advantages, that several countries are given considerable effort to support the SMEs so as to create the necessary employment opportunities, incomes and productive capacity.
In Nigeria, SMEs virtually rely largely on personal savings to grow and innovate ${ }^{2}$. The issue of nepotism and favouritism may not be unconnected to have effect on the overall stable relationships in small business development, which can turn into a weakness ${ }^{3}$. This can adversely affect the business by hindering outsiders with technical know-how to partner and improve on the business. Furthermore, SMEs often lack the financial resources to hire experienced specialists leaving the business into a single owner-managed enterprise ${ }^{2}$. More so it has been opined that even if the owner is willing to share tasks with outsiders, such functions are often not attractive due to the dominance of the owner. This results in many companies relying solely on the owners' knowledge and 
vision, which in most cases are limited to his experience. This has been reported by many researchers to be the bane of conflict in many SMEs personal conflicts and personality clashes, poor leadership style, lack of honesty, stress and clashing values that adversely affects the growth and development of many SMEs in developing countries. SMEs were designed to address these macro economic problems mentioned earlier by providing financial and technical assistance in order to improve these conditions. However, the SMEs face a number of managerial problems, which makes it difficult for them to achieve the stated objectives; these problems may not be unconnected to selection of personnel for employment, poor management etc ${ }^{2,3}$. It is against this background that the researcher feels the need to assess the leadership style and its impact on employee performance in SMEs with a view to finding lasting solutions.

The purpose of this research is to study the effect of leadership style on employee job performance in some selected SMEs in Adamawa State, northeastern Nigeria. The study is expected to bridge any existing gap in literature on the leadership styles in SMEs, with Yola, Adamawa State as a focus. The original instrument used was a questionnaire designed by the researcher, validated and tested to assess its reliability in answering the research questions. The study aims to determine in the selected five firms their leadership styles, and the impact of leadership style in relation to employee performance.

\section{Overview of SMEs in Nigeria}

According to the banker committee of the Central Bank of Nigeria, CBN, a small and medium enterprise is defined as any enterprise with a maximum asset base of N1.5 billion (excluding land and working capital), and with no lower or upper limit of staff. This is subject to review by the Bankers' Committee from time to time ${ }^{4}$. Although the term "SME" is frequently used, it is seldom defined, what constitutes a small, medium or large company is by no means clear or uniform, even within individual countries. In Chile, companies are generally classified according to annual turnover ${ }^{17}$; in South Africa, by turnover, gross asset value and the number of employees $^{16}$. In India, any industrial undertaking with fixed assets less than 10 million Rupees is classed as small-scale ${ }^{15}$. In many cases, these classifications are enshrined in legislation, e.g. in South Africa by the National Small Business Act (1996) and related Amendment Bill (2003) In Nigeria, there is no clear-cut definition that distinguishes a purely small-scale enterprise from a medium-scale enterprise.

The Central Bank of Nigeria ${ }^{4}$, in its Monetary Policy Circular No. 22 of 1988, defined small-scale enterprises as having an annual turnover not exceeding N500,000. In the 1990 budget, the federal government of Nigeria defined small-scale enterprises for purposes of commercial bank loans as those with an annual turnover not to exceed N500,000, and for Merchant Bank Loans, those enterprises with capital investments not exceeding 2 million naira (excluding cost of land) or a maximum of 5 million naira.
The National Economic Reconstruction Fund (NERFUND) put the ceiling for small-scale industries at N10 million. While Section $37 \mathrm{~b}(2)$ of the Companies and Allied Matters Decree of 1990 defines a small company as one with; an annual turnover of not more than 2 million naira; or net asset value of not more than 1 million naira. For the purposes of this study, small and medium-scale enterprises are defined as those with investments in machinery and equipment not exceeding N500,000 and N2 million, respectively, with not more than 50 and 100 paid employees, respectively. This definition does not reflect the characteristics of typical Nigerian small-scale enterprises in terms of their capital base and number of employees ${ }^{4}$.

\section{Importance or Relevance of SMEs to the Economy}

Despite the difficulty of SME's classification, it is clear that the SME sector is highly significant in most economies. For example, in Chile, SMEs account for about 100,000 out of a total of nearly 650,000 production units ${ }^{17}$. Together with medium scale enterprises (MEs), they account for $99 \%$ of Chilean enterprises. MEs and SMEs account for about $50 \%$ of Chilean employment, but less than four per cent of exports $^{17}$. In India, the small scale industrial sector accounts for $95 \%$ of all industrial units, $49 \%$ of manufacturing output, $34 \%$ of exports, $50 \%$ of GDP, and $65 \%$ of employment ${ }^{15}$. In South Africa, it is estimated that about $80 \%$ of the formal business sector and $95 \%$ of the total business sector (including informal) can be considered to be SMEs or MEs, accounting for about $46 \%$ of total economic activity, $84 \%$ of private employment and $97.5 \%$ of all newly registered businesses ${ }^{16}$.

It has been opined that although SMEs individual social and environmental impacts are small, their cumulative impacts are highly significant. In South Africa, small-scale activity in various sectors - including mining and is associated with numerous negative social and environmental impacts $^{5}$. SMEs in Nigeria are the main engine of economic growth and a major factor in promoting private sector development and partnership ${ }^{6}$. In Nigeria, SMEs have been credited with improved living standards, and brought about substantial local capital formation that achieved high level of productivity and capability. Furthermore, SMEs are believed to be the engine room for the development of any economy because they form the bulk of business activities in a growing economy like that of Nigeria ${ }^{6}$. This is manifested in the sector contributing $30 \%$ to global GDP, and employment generation capacity of about $58 \%$ of the global working population to mention but a few ${ }^{6}$. Therefore, the role SMEs play as a principal safety net for the bulk of the population in developing economies such as Nigeria cannot be overstressed. In addition, the employment opportunities they provide reduce rural-urban migration and allows for even development ${ }^{6}$. 


\section{Leadership Characteristics, Styles and Theories}

Leadership is stated as the process of social influence in which one person can enlist the aid and support of others in the accomplishment of a common task ${ }^{7}$. Alan Keith stated that leadership is ultimately about creating a way for people to contribute to making something extraordinary happen ${ }^{8}$. Students of leadership have produced theories involving traits, situational interaction, function, behavior, power, vision and values, charisma, and intelligence among others.

In the past, some researchers have argued that the actual influence of leaders on organizational outcomes is overrated and romanticized as a result of biased attributions about leaders 9 . It has been shown that the ability to attain these unique powers is what enables leadership to influence subordinates and peers by controlling organizational resources ${ }^{10}$.

\section{Leadership Styles}

Leadership style refers to a leader's behaviour. It is the result of the philosophy, personality and experience of the leader. The different styles of leadership are Autocratic, Participative, and Laissez-Faire ${ }^{11}$.

Autocratic or authoritarian style: Under the autocratic leadership style, all decision-making powers are centralized in the leader, as with dictator leaders. They do not entertain any suggestions or initiatives from subordinates.

Participative or democratic style: The democratic leadership style favors decision-making by the group such as leader gives instruction after consulting the group.

Laissez-faire or free rein style: A free rein leader does not lead, but leaves the group entirely to itself as shown; such a leader allows maximum freedom to subordinates, i.e., they are given a free hand in deciding their own policies and methods. Different situations call for different leadership styles.

\section{Designs and Methods}

This quantitative study aims to answer the research questions and test the hypotheses. This study design is crosssectional studies in the form of a survey. The rationale for selecting the cross sectional design is because it serves as a definitive and objective way to study and describe actions; measure level of occurrence, actions and trends; measure how many members of a population have particular knowledge, attitudes, or engages in a particular behavior ${ }^{12}$. The result from this research design, especially when selection of interviewees is done well, would truly be representative of the surveyed population. The advantage of this design lies in the fact that it uses a sample to make generalizable claims or conclusions on a given population ${ }^{12}$.

The research questions for this study are:

RQ1 - Do SMEs in Adamawa State employ leadership styles in their businesses?
RQ2 - Do leadership style have impact on employee performance in SMEs in Adamawa State?

The hypotheses to be tested in this study are:

Hypothesis 1: There is no significant relationship between the type of enterprise and leadership style.

Hypothesis 2: There is no significant relationship between leadership style and employee performance in the SMEs

The considered population for this study is 179 (executive directors and non executive directors) staff from five firms selected for this study: Wampa bakery (8 management staff and 71 employees), Jimeta bakery (6 management staff and 62 employees), Cleanstar laundry services (a manager and 3 employees), Frankbytes ventures (3 management staff and 15 employees) while Lovely and Edible enterprises (2 management staff and 8 employees). Thus, the target population is made up of 21 management staff and 158 employees. The research is concerned with leadership style and employee performance in the selected SMEs between the time periods of March 2010 to February 2011.

Considering the fact that it is not possible to study the entire population due to time constraint and lack of resources, this study used a probability sampling strategy to select a sample size that is truly be representative of the population of interest for the outcome to be generalizable; this ensures that every member of the population has equal chance of participating in this study and to give credence to the outcome. The sample size for this study was 100 (21 management staff and 79 employees) selected using the $\mathrm{G}^{*}$ power statistical tool ${ }^{13}$, medium effect size of 0.5 , alpha level of significance of 0.05 , and df of 5 .

This study distributed a closed-ended questionnaire to the selected participants. The purpose of the study was clearly written on the questionnaires for the respondents to understand the objectives.

The measurement scale used in this quantitative research was nominal, ordinal and interval type of measurement to effectively answer the research questions. The ordinal uses likert scale to reduce cognitive complexity in the form of presenting individuals with a single dimension.

The study assessed both internal and external validity to know if internal validity assesses the relationship between the variables $^{12}$. Furthermore, this study took note of the possible biases that could occur in various ways ranging from the design to measurement of the variables. The two biases that this study took cognizance are selection bias and information bias; these could potentially compromise internal validity of the results. This research pilot tested the questionnaire to assess reliability and validity of the measurement of constructs of interest on a small subset of the target population $^{12}$.

Data analyses will be based on the weighted samples using SPSS version 13. The SPSS version 17 will be used to account for the complex sampling design of the survey and weighted observations. Statistical tools like percentages and mean score was used to analyze objectives one, while Chi square was used to analyze objective two. 


\section{Results and Analysis}

Out of the 100 questionnaires distributed to respondents in the five different firms out of which 85 were duly completed and returned. This implies that the analysis here is 85 per cent reliable. The individual questionnaires were sorted manually and information of each of the five selected firms extracted and tabulated accordingly as shown below. Descriptive statistics was used and Chi square analysis employed to be able to derive some inferences from the study.

Table 1. Distribution of Respondents according to Firms.

\begin{tabular}{lll}
\hline Firm & Frequency & Percentage (\%) \\
\hline Frankbyte & 15 & 17.65 \\
Lovely and Edible & 21 & 24.71 \\
Cleanstar & 25 & 29.41 \\
Jimeta Bakery & 11 & 12.94 \\
Wampa Bakery & 13 & 15.29 \\
Total & 85 & 100.00 \\
\hline
\end{tabular}

Table 1 shows that Cleanstar $25(29.41 \%)$ has the percentage distribution of responses and Jimeta Bakery 11 $(12.94 \%)$ had the least.

Table 2. Distribution of Respondents according to Gender.

\begin{tabular}{lll}
\hline Gender & Frequency & Percentage (\%) \\
\hline Male & 37 & 43.50 \\
Female & 48 & 56.50 \\
Total & 85 & 100.00 \\
\hline
\end{tabular}

Table 2 shows that the highest respondents were females $48(56.50 \%)$ with males occupying the remaining 37(43.50).

Table 3. Distribution of Respondents according to Age.

\begin{tabular}{lll}
\hline Age & Frequency & Percentage $\mathbf{( \% )}$ \\
\hline$<20$ years & 5 & 5.88 \\
$20-29$ years & 23 & 27.06 \\
$30-39$ years & 44 & 51.76 \\
$40-49$ years & 12 & 14.12 \\
$>50$ & 1 & 1.18 \\
Total & 85 & 100.00 \\
\hline
\end{tabular}

Table 3 shows that highest respondents were in their active age group 30-39(14.12\%) while the least were those aged $>50(1.18 \%)$.

Table 4. Distribution of Respondents according to Educational level.

\begin{tabular}{lll}
\hline Nature of employment & Frequency & Percentage (\%) \\
\hline Non formal & 5 & 5.90 \\
Primary & 11 & 12.90 \\
Secondary & 50 & 58.80 \\
Tertiary & 19 & 22.40 \\
Total & 85 & 100.00 \\
\hline
\end{tabular}

Table 4 shows that $50(58.80 \%)$ of the respondents attended secondary school, while the least were those with non-formal education $5(5.90 \%)$.
Table 5. Distribution of responses on whether managers permit selfdiscretion.

\begin{tabular}{lll}
\hline Nature of employment & Frequency & Percentage (\%) \\
\hline Strongly disagree & 4 & 4.70 \\
Disagree & 14 & 16.50 \\
Undecided & 21 & 24.70 \\
Agree & 21 & 24.70 \\
Strongly agree & 25 & 29.40 \\
Total & 85 & 100.00 \\
\hline
\end{tabular}

Table 5 above showed a picture occupying the extremes; respondents who strongly agree that there manager's permits self-discretion were the highest with $29.40 \%$ whereas those who strongly disagree occupied the least percentage (4.70\%). This type of leadership most common in the five firms is democratic in nature as manager gives them freedom or ability in decisions.

Table 6. Distribution of responses on how leaders are elected.

\begin{tabular}{lll}
\hline Nature of employment & Frequency & Percentage (\%) \\
\hline Strongly disagree & 12 & 14.10 \\
Disagree & 16 & 18.80 \\
Undecided & 14 & 16.50 \\
Agree & 20 & 23.50 \\
Strongly agree & 23 & 27.10 \\
Total & 85 & 100.00 \\
\hline
\end{tabular}

In table 6 above, those who strongly agree $(27.1 \%)$ and agree $(23.5 \%)$ that leaders in their respective firms are elected were the highest whereas those who strongly disagree to that were the least $(14.1 \%)$. This shows that in the firms leadership is participative or democratic as such the leaders will be able to command respect and guide them to specific task, which defines leadership.

Table 7. Distribution of responses on staff attitude surveys by employers.

\begin{tabular}{lll}
\hline Nature of employment & Frequency & Percentage (\%) \\
\hline Strongly disagree & 3 & 3.53 \\
Disagree & 3 & 3.53 \\
Undecided & 21 & 24.71 \\
Agree & 45 & 52.94 \\
Strongly agree & 13 & 15.29 \\
Total & 85 & 100.00 \\
\hline
\end{tabular}

In table 7 above, those who agree that there are staff attitude surveys conducted by their employers were the highest with $52.94 \%$ while the least responses on that came from two of the groups: those who strongly disagree as well as those who disagree, each with $3.53 \%$ respectively. This finding buttresses the fact in table 6 that the leadership in the firms is participative and democratic. Kurt Lewin states that democratic style leaders can win the cooperation of their group and can motivate them effectively and positively.

The Chi square $\left(\chi^{2}\right)$ test is used to determine whether there is a significant difference between the expected frequencies and the observed frequencies in one or more categories. A Chi-square test is used in this study to test if there is a relationship between organizational effectiveness and relationship between managers and employees. The tables 8 and 9 are the cross tabulation of the two hypotheses and 
summary of the Chi

If the computed value of Chi square $\left(\chi^{2}\right)$ is greater than the tabulated value at $95 \%$ degree of freedom, the null hypothesis $\left(\mathrm{H}_{0}\right)$ should be rejected.

Table 8. D1*F2 cross tabulation Hypothesis I.

\begin{tabular}{|c|c|c|c|c|c|c|}
\hline & & & D1 & & & \\
\hline F2 & Strongly disagree & Disagree & Undecided & Agree & Strongly Agree & Total \\
\hline Strongly disagree & & 2 & & & 1 & 3 \\
\hline Disagree & 1 & 1 & 2 & 1 & 1 & 6 \\
\hline Undecided & 2 & & & 1 & 3 & 6 \\
\hline Agree & 3 & 4 & 4 & 13 & 12 & 36 \\
\hline Strongly Agree & 4 & 2 & 3 & 6 & 19 & 34 \\
\hline TOTAL & 10 & 9 & 9 & 21 & 36 & 85 \\
\hline
\end{tabular}

Table 9. D1* A5 cross tabulation Hypothesis II.

\begin{tabular}{|c|c|c|c|c|c|c|}
\hline & & & D1 & & & \\
\hline A5 & Strongly disagree & Disagree & Undecided & Agree & Strongly Agree & Total \\
\hline Bakery & 1 & 1 & 4 & 8 & 8 & 22 \\
\hline Laundry & 6 & 5 & 1 & 6 & 7 & 25 \\
\hline Catering & 3 & 3 & 4 & 7 & 21 & 38 \\
\hline TOTAL & 10 & 9 & 9 & 21 & 36 & 85 \\
\hline
\end{tabular}

The cross tabulation of the summary to determine the predominant type of leadership common in the five SMEs in relation to employee performance (Table 8) shows that the employees agree that the type of leadership in the five business (firms) is democratic as supported by the number of respondents with 36 agreeing $(42.4 \%)$ and 34 strongly agreeing (40\%).

Table 10. Chi Square Tests Hypothesis 1

\begin{tabular}{llll}
\hline & Value & Df & Asymp. Sig. (2-sided) \\
\hline Pearson's chi square & 24.550 & 16 & 0.078 \\
Likelihood ratio & 20.669 & 16 & 0.192 \\
Linear-by-linear association & 3.709 & 1 & 0.054 \\
N of valid cases & 85 & & \\
\hline
\end{tabular}

Looking at the Chi Square tests result in table 10, the result of the computed Chi square value of $24.55(\mathrm{P}=0.05)$ with 95 $\mathrm{df}$ clearly shows that it is greater than the tabular value of $0.078(\mathrm{P}=0.05)$ thus we reject hypothesis 2 which states that: "There is no significant relationship between leadership style and employee performance in the SMEs." This clearly implies that leadership style does influence employee performance. Thus, effective leadership can be immense with regard to employee performance as the important building block of an organization ${ }^{14}$.

The cross tabulation of the summary to determine the relationship between type of enterprise and leadership style in the five SMEs is presented in table 9. The descriptive shows that the catering services had the highest responses of 21 respondents as strongly agree as having a relationship between type of enterprise and leadership style, while the least response of 8 was in bakery.

Table 11. Chi Square Tests Hypothesis 2.

\begin{tabular}{llll}
\hline & Value & Df & Asymp. Sig. (2-sided) \\
\hline Pearson's chi square & 17.385 & 12 & 0.136 \\
Likelihood ratio & 17.933 & 12 & 0.118 \\
Linear-by-linear association & 0.895 & 1 & 0.344 \\
N of valid cases & 85 & & \\
\hline
\end{tabular}

On the second hypothesis the Chi Square is $17.39(\mathrm{P}=0.05)$ with $95 \mathrm{df}$ as shown in table 11, the distribution of responses shows that 36 strongly agree that there is no significant relationship between type of enterprise and leadership style in the SMEs, 21 respondents agree to the same fact while those that strongly disagree had 10 respondents (Table 9). Therefore going by the computed $\chi^{2}$ (chi square) value of $17.39(\mathrm{P}=0.05)$, as compared to the tabular value of 0.136 $(\mathrm{P}=0.05)$ we conclude by rejecting the Null hypothesis which states: "There is no significant relationship between the type of enterprise and leadership style in the SMEs." This is buttress by the descriptive shown in Table 6 where all the respondents said the leadership is democratic.

\section{Research Findings}

This research discovered that there was a significant relationship between leadership style and employee performance, and that leadership style is participative democracy. The Chi square test of the hypotheses revealed that the computed values (24.55 and 17.39) for the first and second hypotheses at $(\mathrm{P}=0.05,95$ degree of freedom $)$ are greater than the tabulated values $(0.078$ and 0.136$)$ at $(\mathrm{P}=0.05$, 95 degree of freedom). This implies that leadership style did influence employee performance and that there was significant relationship between type of enterprise and leadership style in the SMEs.

\section{Conclusion}

This study concludes that the predominant type of leadership in the five firms was participative democracy, that leadership style had effect on employee performance and also type of enterprise had effect on leadership style. It therefore recommends that for workers to put in their best in any organisation, leaders should be democratic and involve workers in decision-making. 


\section{References}

[1] Aderemi, S. A(2003). Marketing: principles and practice. Concept Publishing Limited, Mushin Lagos

[2] Ekpenyong, D. B. and M.O. Nyong (1992). Small and medium-scale enterprises in Nigeria: their characteristics, problems and sources of finance. African Economic Research Consortium, Nairo AERC Research Paper 16. AERC P.O. Box 62882, Nairobi, Kenya.

[3] Mambula C (2002). Perceptions of SME Growth Constraints in Nigeria. Journal of Small Business Management 40(1), pp. $58-61$

[4] Central Bank of Nigeria (2006). Annual Reports.

[5] International Union for Conservation of Nature (2004). Retrieved from http://www.iucn.org/about/union/secretariat/offices/asia/asia where_work/pakistan/publications/pubs_2004/

[6] Skillsforbusiness (2007). SME's and Entrepreneurship. Retrieved from http://www.skillsbusiness.org

[7] Chemers, M. M. (2002). Meta-cognitive, social, and emotional intelligence of transformational leadership: Efficacy and Effectiveness. in Riggio R.E, Murphy S.E, Pirozzolo,F.J(Eds.), Multiple Intelligences and Leadership. in: Leadership.

[8] Kouzes, J. \& Posner, B. (2007). The Leadership Challenge. CA: Jossey Bass.

[9] Meindl, J. R., \& S. B. Ehrlich, (1987). The romance of

leadership and the evaluation of organizational performance. Academy of Management Journal 30(1): 91-109.

[10] Montana, P. J. and C. H. Bruce (2008) Management: Leadership and Theory, 4th English edition, Barron's Educational Series, Inc., Hauppauge, New York.

[11] Lewin, K., Lippitt, R., \& R.K. White (1939). "Patterns of aggressive behavior in experimentally created social climates". Journal of Social Psychology 10: 271-301.

[12] Creswell, J. (2009). Research design: Qualitative, quantitative, and mixed methods approaches (3rd ed.). Thousand Oaks, CA: Sage Publications.

[13] Faul, F., Erdfelder, E., Lang, A., \& Buchner, A. (2007). $G^{*}$ Power 3: A flexible statistical power analysis program for the social, behavioral, and biomedical sciences. Behavior Research Methods 2007, 39 (2), 175-191.

[14] Gadot, E.V. (2007). Leadership style, organizational politics and employee performance: An empirical examination of two competing models. Personnel Review 36(5): 661-683.

[15] India Economic Times (2008). Retrieved from http://www.economictimes.indiatimes.com.

[16] South African National Small Business Amendment Act (2004). Retrieved from www.thedti.gov.za/business.../acts/small_business_amendmen t_act.pdf.

[17] Issue Briefing Note: Small and Medium-Sized Enterprises (2004). Retrieved from www.iisd.org/pdf/2004/standards_sme.pdf. The International Institute for Sustainable Development, Canada. 